\title{
Calibration of Hydrognomon Model for Simulating the Hydrology of Urban Catchment
}

\author{
Haruna Garba ${ }^{1}$, Abubakar Ismail ${ }^{2}$, Folagbade Olusoga Peter Oriola ${ }^{1}$ \\ ${ }^{1}$ Department of Civil Engineering, Nigerian Defence Academy, Kaduna, Nigeria; ${ }^{2}$ Department of Water Resources and Environ- \\ mental Engineering, Ahmadu Bello University, Zaria, Nigeria. \\ Email: garba.haruna@ymail.com, garbaharuna84@gmail.com, abuismail1@yahoo.com, Oree21257@yahoo.com
}

Received August $8^{\text {th }}, 2012$; revised September 15 ${ }^{\text {th }}, 2012$; accepted September $25^{\text {th }}, 2012$

Copyright (c) 2013 Haruna Garba et al. This is an open access article distributed under the Creative Commons Attribution License, which permits unrestricted use, distribution, and reproduction in any medium, provided the original work is properly cited.

\begin{abstract}
Due to chaotic nature of flow in natural open channels and the physical processes and the unknown in a river basin variable, the parameters to be used in studying the behavior of river basin to a given rainfall data cannot be measured directly for this reason, a hydrological model was calibrated and applied to simulate the hydrology of Kaduna River (7112 sq miles) North West Nigeria. Prior to the model calibration, a sensitivity analysis of the hydrognomon model to the parameters was carried out to gain a better understanding of the correspondence between the data and the physical processes being modeled.
\end{abstract}

Keywords: Calibration; Model; Optimization; Flood; Stream Flow; Parameter

\section{Introduction}

Across the globe, human populations are becoming increasingly urban with approximately fifty percent of the worlds population residing in urban areas as observed by [1]. Continued land development and land use changes within cities present considerable challenges for environmental management. [2] observed that hydrologic changes including increase impervious area, soil compaction and increased drainage efficiency generally lead to increase direct runoff, decreased ground water recharge and increase flooding cited by [3]. Increase stream stage and discharge variability are the common responses to urbanization. [4] observed that urban streams are susceptible to the occurrence of extreme flow event than their rural counterpart. Furthermore, according to [4] changes in peak flow due to urbanization vary with the degree of urban development, recurrence interval of the peak flow and location within the water shed.

Hydrological models especially the simple rainfallrunoff types are widely used in understanding and quantifying the impacts of land use changes and provide information that can be used in land use decision making. Furthermore [5], observed that the frequency of occurrences of extreme flood due to climate changes have increased the need for better understanding of floods.

Understanding the behavior of a river basin to a given rainfall volume depends on the analysis of rainfall data which helps to provide information about data with regards to the variable under study. The probability distribution is a hydrological tool most widely used in flood estimation and prediction Probability distribution functions have been used to model phenomenon characterized by significant variability such as rainfall in contrast to deterministic approach determined by physical principles. Parameters of distribution functions are characteristics of rainfall data which helps to provide information about the data with regards to the variable under study. Due to parametization of the physical processes and the unknown in the basin characteristics parameters to be used cannot be measured directly; they are therefore obtained by a process of model calibration.

Model calibration according to [6] is the procedure of demonstrating that the model can produce field measured quantities such as hydraulic heads and flows. It is carried out by finding set of parameters and boundary conditions that produce simulation results that is in agreement with field measured data. The objective of model calibration is maximize the coefficient of efficiency by reducing the percentage difference in mean, standard deviation and coefficient of variation between the predicted and observed stream flow. Calibration of a rainfall-runoff model with respect to local observational data will help to improve model predictability as observed by [3]. When 
model results match observed values from stream flow measurement, there is greater confidence in the reliability of the model.

The model was calibrated and applied to simulate the hydrology of Kaduna River under various climatic conditions as part of a $\mathrm{PhD}$ study by [5].

\section{Materials and Methods}

\subsection{The Model}

Hydrognomon is an open sources software tool used for the processing of hydrological data (Figure 1). Data are usually imported through standard text files, spread sheets or by typing. The available processing techniques for the tool includes time step aggregation and regularization, interpolation, regression analysis and infilling of missing values, consistency test, data filtering, graphical and tabular visualization of time series. Hydrognomon support several time step from the finest minutes scales up to decades. The programme also include common hydrological application such as evapotranspiration modeling, stage discharge analysis, homogeneity test, areal integration of point data series, processing of hydrometric data as well as lumped hydrological modeling with automatic calibration facilities as contained in the hydrognomon user manual (http:www.hydrognomon.org) [7].

\subsection{The Study Area}

Kaduna Township located between latitudes $10^{\circ} 27^{\prime} 15^{\prime \prime} \mathrm{N}$ $10^{\circ} 13^{\prime} 5 " \mathrm{~N}$ and Longitudes $7^{\circ} 21^{\prime} 48^{\prime \prime} \mathrm{E}-7^{\circ} 29^{\prime} 36^{\prime \prime} \mathrm{E}$ in the high plains of North western Nigeria region (Figure 2). The general relief of the area is an undulating plain land at a height of between $582 \mathrm{~m}$ to $640 \mathrm{~m}$ [8]. Kaduna state experiences a typical continental climate with distinct seasonal regimes. The spatial and temporal distribution of rainfall varies over Kaduna. The soils and vegetation

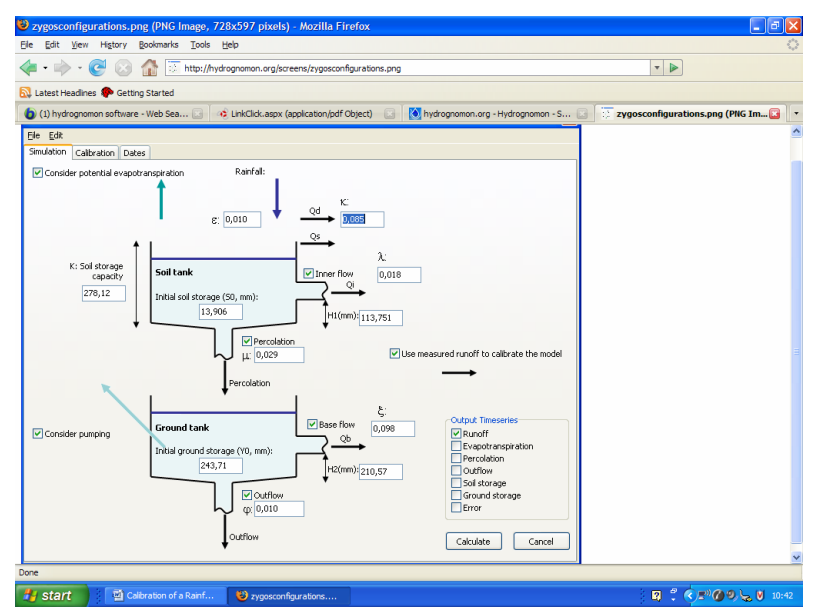

Figure 1. Structure of the simulation/calibration module (http: www.hydrognomon. org). area typical of red brown to red yellow tropical soils and savanna grass land comprising of scattered trees and woody scrubs.

Kaduna river is the main tributary of Niger river in central Nigeria. It rises on the Jos plateau south west of Jos town in a North West direction to the northeast of Kaduna town (Figure 3). It then adopts a south westerly and southerly course before completing its flow to the Niger River at Mureji. Most of its course passes through open savanna woodlands but its lower section cut several gorges including the granite ravine at Shiroro above its entrance into the extensive Niger flood plains.

\subsection{Data Used}

The historical data used for the calibration were recorded rainfall and gauge height levels from 1975-2000 (26 years) of record at a gauging point (Datum at $582.96 \mathrm{~m}$ ) located in the study area at Kaduna south water works. The data are totals on monthly basis spanning the calibration period. The steps of the data collection process

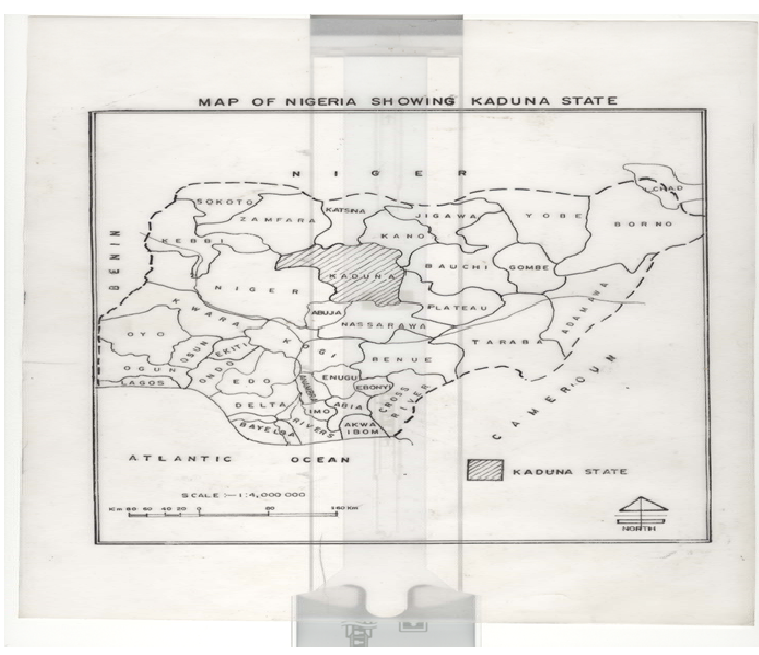

Figure 2. Location of Kaduna state on map of Nigeria.

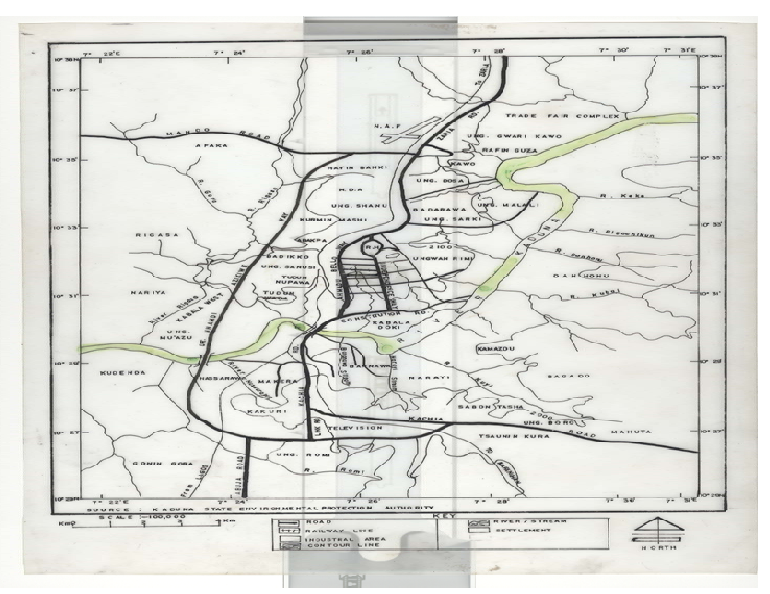

Figure 3. Location map of the study area (Kaduna River). 
involve the following:

- The daily stream flow was read as gauge height while the daily rainfalls were read for each of the stations.

- The monthly maximum stream flow values and rainfall values were extracted from the daily values.

- The gauged levels measured were used to scale the flow to runoff volume of the watershed by using the expression below [9] in calibrating the model.

$$
\mathrm{Q}=\mathrm{ICA}
$$

where

$$
\begin{aligned}
& \text { Q = calculated runoff; } \\
& \text { I = gauged water levels; }
\end{aligned}
$$

$\mathrm{C}=\mathrm{a}$ factor (distribution coefficient) the ratio maximum gauge level at a point tothe mean gauge levels of Kaduna river.

$$
\mathrm{A}=\text { drainage area of Kaduna river. }
$$

\section{Results and Discussions}

Before calibrating, the sensitivity analysis of the hydrognomon model to the flow parameters was tested. The hydrognomon model is most sensitive to the flow recession parameters in both the initial soil storage and the initial ground water storage. The recession parameters control the ability of the soil to retain water in the two storages, the model is insensitive to the capillary flow and the coefficient of base flow is insignificant in simulating the flow.

The physical processes on the basin scale and the unknowns in the basin characteristics consist of too many parameters which cannot be measured directly, for this reason the model was calibrated. Figure 4 shows the observed and simulated runoff. The actual runoff was calibrated with the calculated runoff at an objective function of 0.993 [10]. Prior to the model calibration, a sensitivity analysis of the hydrognomon model to the soil parameters have been tested. For the test of each parameter, all the others were fixed and the tested parameter was change from the lower to the upper boundary on a discrete value and applied to the model (Figure 4). The table below shows parameters calibrated in the study together with their upper and lower boundaries. The model was calibrated at an objective function of 0.390 with 8001 iterations. The parameter calibrated in this study with lower and upper boundaries is in the Table 1 below.

\section{Conclusion}

Due to the fact that the physical processes at the river basin scale and the unknown in the basin characteristics consist of too many parameters which cannot be meas-ured directly the model was thus calibrated. The model is most sensitive to the flow recession parameters of both the lower and the upper tanks. The calibrated results showed the Nash and Sutcliffe efficiency of $>9$. The pa-

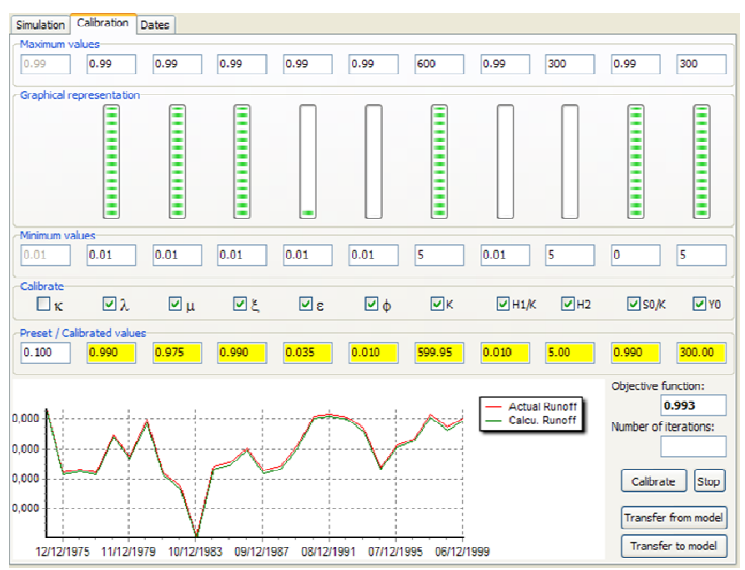

Figure 4. Predicted and simulated monthly flow for Kaduna River.

Table 1. Parameters calibrated in the study with their minimum and maximum values.

\begin{tabular}{cccc}
\hline Parameter & $\begin{array}{c}\text { Lower } \\
\text { boundary }\end{array}$ & $\begin{array}{c}\text { Upper } \\
\text { boundary }\end{array}$ & $\begin{array}{c}\text { Sensitivity } \\
\text { level }\end{array}$ \\
\hline $\begin{array}{c}\text { Soil storage } \\
\text { capacity }(\kappa)\end{array}$ & & 0.990 & $\begin{array}{c}\text { Insensitive } \\
\text { Highly } \\
\text { Coefficient for } \\
\text { inner flow }(\lambda)\end{array}$ \\
$\begin{array}{c}\text { Percolation } \\
\text { coefficient }(\mu)\end{array}$ & 0.01 & 0.975 & $\begin{array}{c}\text { Highly } \\
\text { sensitive }\end{array}$ \\
$\begin{array}{c}\text { Evaporation }(\varepsilon) \\
\text { Coefficient for } \\
\text { out flow }(v)\end{array}$ & 0.01 & 0.035 & $\begin{array}{c}\text { Insensitive } \\
\text { Coefficient for } \\
\text { surface runoff } \\
\text { flow }(\kappa)\end{array}$ \\
$\begin{array}{c}\text { H1/ } \kappa \\
\text { Threshold for }\end{array}$ & 0.00 & 0.010 & Insensitive \\
creating base flow \\
$\quad$ (H2)
\end{tabular}

rameters of $\lambda$ (0.99), $\mu$ (0.975), $\kappa$ (599.95), S0/ $\kappa$ (0.990), $\gamma_{o}(300)$ and $\xi(0.990)$ can be transferred to the model and applied to simulate the hydrology of Kaduna River for hydrological investigation.

\section{REFERENCES}

[1] J. Cohen, "Human Populations: The Next Centaury," Science, Vol. 302, No. 5648, 2003, pp. 1172-1175. doi:10.1126/science. 1088665

[2] D. Booth, "Urbanization and Natural Drainage SystemImpact, Solutions and Prognoses," Northwest Environ- 
mental Juornal, Vol. 7, pp. 93-118.

[3] S. Muthukrisman, J. Harbour, K. J. Lim and B. A. Engel, "Calibration of a Simple Rainfall-Runoff Model for LongTerm Hydrological Impact Evaluation,” URISA Journal, Vol. 18, No. 2, 2006, pp. 35-42.

[4] O. M. Driscol, S. Clinton and A. Jefferson, "Urbanization Effect on Watershed Hydrology and In-Stream Processes in the Southern United States,” Water, Vol. 2, No. 3, 2010, pp. 605-645. doi:10.3390/w2030605

[5] H. Garba, "Predicting the Potential Effect of Climate Change on the Hydrological Response of Kaduna River North West Nigeria Using Hydrological Model," Ph.D. Thesis, Department of Civil Engineering, Nigerian Defence Academy, Kaduna, 2013.

[6] D. Potcrajac and K. Howard, "Advanced Simulation and Modeling for Ground Water Management,” The United Nations Education, Scientific and Cultural Organization
(UNESCO), Paris, 2010.

[7] EGU, “Hydrognomon,” 2010, Vienna. http://www.hydrognomon.org

[8] N. D. Jeb and S. P. Aggarrwal, "Flood Inundation Hazard Modeling of the River Kaduna Using Remote Sensing and Geographical Information Systems,” Journal of Applied Science Research, Vol. 4, No. 12, 2008, pp. 18221833.

[9] K. D. W. Nandala, “CE 205 Engineering Hydrology Lecture Notes,” Department of Civil Engineering, University of Peradeniya, Peradeniya.

[10] J. E. Nash and J. V. Sutcliffe, "River Flow Forecasting through Conceptual Models, a Discussion of Principles," Journal of Hydrology, Vol. 10, No. 3, 1970, pp. 282-291. doi:10.1016/0022-1694(70)90255-6 